\title{
Cannabinoid Receptor 1 Gene by Cannabis Use Interaction on CB1 Receptor Density
}

Ariel Ketcherside, ${ }^{1,2, *}$ Lindsey J. Noble, ${ }^{2}$ Christa K. Mclntyre, ${ }^{2}$ and Francesca M. Filbey ${ }^{1,2}$

\begin{abstract}
Background: Because delta-9-tetrahydrocannabinol (THC), the primary psychoactive ingredient in cannabis, binds to cannabinoid 1 (CB1) receptors, levels of CB1 protein could serve as a potential biomarker for response to THC. To date, available techniques to characterize CB1 expression and function in vivo are limited. In this study, we developed an assay to quantify CB1 in lymphocytes to determine how it relates to cannabis use in 58 daily cannabis users compared with 47 nonusers. Furthermore, we tested whether CB1 levels are associated with mutations in a single nucleotide polymorphism known to regulate CB1 functioning (i.e., rs2023239).

Methods: Total protein concentration was analyzed through the Pierce BCA Protein assay kit. CB1 protein was quantified through CNR1 enzyme-linked immunosorbent assay (ELISA) kit from MyBioSource. CB1 concentration and total protein concentration were quantified and used to calculate a ratio of CB1 to total protein.

Results: Inherent levels of peripheral lymphocyte CB1 were sufficient for quantification through ELISA without protein amplification. We found a group $\times$ genotype interaction such that users with the $G$ allele had greater CB1 concentration than users with the A/A genotype, and a trend-level difference between genotypes in nonusers. Conclusions: This study demonstrates a minimally invasive technique of $\mathrm{CB} 1$ quantification that holds promise for the use of CB1 protein concentration, along with rs 2023239 genotype, as a potential biomarker for susceptibility to cannabis use. These results suggest a gene (rs2023239 G) × environment (cannabis use) effect on CB1 density.
\end{abstract}

Keywords: biomarker; cannabis; cannabinoid receptor 1; orbitofrontal cortex; peripheral lymphocytes

\section{Introduction}

The human cannabinoid 1 (CB1) receptor is part of the endocannabinoid system (ECS), which is highly regulatory in various functions throughout the body, including the central nervous system (CNS) and the digestive, reproductive, and urinary tracts. ${ }^{1,2}$ The primary psychoactive component of cannabis, delta-9-tetrahydrocannabinol (THC), binds to $\mathrm{CB} 1$, and this binding in the CNS is responsible for the psychoactive effects of cannabis. Specifically, THC binds to CB1 receptors in the ventral tegmental area, which disinhibits dopaminergic signaling and results in a reward response. ${ }^{3}$ Evidence for $\mathrm{CB} 1$ variability exists in the single nucleotide polymorphism (SNP) rs2023239, which may code for an alternative of the CB1 protein. ${ }^{4}$ The $\mathrm{G}$ (risk) allele at this locus causes alternative splicing of CNR1. ${ }^{4,5}$ Variability at this location has been associated with craving and withdrawal in heavy cannabis users $^{6}$ as well as proclivity toward cannabis use disorders. ${ }^{7}$ Thus, on a molecular level, the rewarding effects of cannabis may be associated with the $G$ allele and CB1 concentration.

Results from animal studies examining CB1 expression after long-term exposure to THC are mixed. Burston et al. reported an overall downregulation of CB1 in adolescent female rats after THC administration for $\sim 10$ days, mimicking long-term use in humans. This

${ }^{1}$ Center for BrainHealth, University of Texas at Dallas, Dallas, Texas.

${ }^{2}$ The School of Behavior and Brain Science, University of Texas at Dallas, Dallas, Texas. 
downregulation was more pronounced in females, particularly in the ventral midbrain, hippocampus, and prefrontal cortex, indicating variable effects of THC throughout the CNS. ${ }^{8}$ Conversely, Zhuang et al. found an increase in CB1 mRNA in the cerebellum and hippocampus of male rats after 21 days of exposure, whereas it decreased in the striatum. ${ }^{9}$ The incongruity of these results in animals may be because mRNA and protein do not always change in the same direction, depending on timing of measurements and other factors.

In humans, there is evidence for altered CB1 expression in the brain after long-term cannabis use. One postmortem in situ radioligand binding study found increased CB1 binding in the caudate and putamen of individuals who had consumed cannabis within 5 days of death compared with controls. ${ }^{10}$ Another group demonstrated that CB1 binding in postmortem pituitary adenomas correlated with levels of endogenous cannabinoids, indicating a positive relationship between cannabinoid availability and receptor expression. ${ }^{11}$ However, in known daily users, radioligand binding demonstrated decreased CB1 binding across all brain regions compared with controls. ${ }^{12}$ Similarly, studies using positron emission tomography (PET) have reported that $\mathrm{CB} 1$ expression in the brains of heavy cannabis users negatively correlates with years of smoking, returns to normal levels upon abstinence, ${ }^{13}$ and a negative correlation exists between general $\mathrm{CB} 1$ binding and age in all regions examined. ${ }^{14}$ In sum, these studies suggest that CB1 density is related to THC exposure, but characterization of CB1 expression and density is still in its infancy. ${ }^{15,16}$ Furthermore, the effect of rs2023239 on CB1 density, compounded with frequent cannabis use, remains unknown. Thus, a noninvasive measurement of CB1 changes in living humans is necessary and would facilitate the understanding of how cannabis affects cellular mechanisms over time.

Although $\mathrm{CB} 1$ is most dense in the $\mathrm{CNS},{ }^{17}$ it also exists in peripheral tissues ${ }^{18}$ where it is similarly regulatory. THC's binding to CB1 has been shown to alter immune function in rodents, ${ }^{19}$ indicating that exogenous cannabinoids may induce changes in these lymphocytes directly through cannabinoid receptor activation. In addition, THC has been shown to downregulate proinflammatory cytokines in human peripheral lymphocytes. ${ }^{20}$ Thus, a measure of peripheral CB1 could be a valuable tool with implications for CNS function, particularly when examined in cannabis users versus nonusers.
One avenue that holds promise for quantifying in vivo human $\mathrm{CB} 1$ expression is through lymphocytes, as they are easily accessible and the role of cannabinoids in immune function suggests high $\mathrm{CB} 1$ expression. $^{21-23}$ Despite methodological difficulties, ${ }^{24}$ the presence and activity of CB1 in peripheral lymphocytes have been established through various means in previous studies. ${ }^{25-27}$ However, quantification methods are limited, as available antibodies are notably unreliable, and other methods (e.g., flow cytometry and radioactive ligand assays) are expensive. Furthermore, changes in peripheral CB1 levels in relation to cannabis use have not been directly investigated. This warrants investigation because $\mathrm{CB} 1$ promoter region methylation and mRNA expression in other human tissues have exhibited a difference between cannabis users and nonusers. For example, Rotter et al. $^{28}$ used quantitative real-time polymerase chain reaction (PCR) to study potential changes in $\mathrm{CB} 1$ expression in peripheral blood cells of 77 subjects with varying degrees of cigarette and cannabis use and found a decrease in expression in THC-dependent participants, as well as a negative correlation between promoter methylation and CB1 mRNA. Methylation and mRNA analysis provide information about up- or downregulation in a protein's expression, but do not unequivocally indicate the result of that protein's expression. Thus, although these methods are informative, they require corroboration with actual CB1 concentration.

The aim of this study was to test a novel method of CB1 quantification through lymphocytes in humans and determine how peripheral CB1 levels may relate to known genetic and environmental modulators. Specifically, because CB1 agonists, such as THC, have been shown to downregulate $\mathrm{CB} 1$ receptors, we hypothesized that peripheral CB1 would be decreased in chronic cannabis users relative to nonusing controls and that CB1 would be negatively correlated with THC metabolite levels. Furthermore, because rs2023239 genotype has been associated with CB1 expression, ${ }^{4-6}$ we also expected that carriers of the rs $2023239 \mathrm{G}$ allele would show downregulation of CB1. Last, we expected a genotype (rs2023239) $\times$ environment (THC exposure) interaction similar to what has been previously reported, ${ }^{29}$ such that rs2023239 will moderate the effects of THC exposure on CB1 lymphocytes.

\section{Materials and Methods}

The Institutional Review Board of the University of Texas at Dallas and University of Texas Southwestern 
Medical Center approved these study procedures. All experiments were conducted according to the principles expressed in the Declaration of Helsinki.

\section{Participants}

One hundred twenty-one participants from a larger study of cannabis use ${ }^{30}$ took part in this study. The participants were recruited from the general community in the Dallas/ Fort Worth metro area through media advertisements and were financially compensated for their participation. As the larger study included neuroimaging, all participants were right handed and had no MRI contraindications. All participants spoke English as their primary language, and reported no neurological conditions, axis I psychiatric disorders, or traumatic brain injury. The absence of all other drug use (besides cannabis in users) was verified through urinalysis and all participants reported smoking $<20$ cigarettes per month.

Peripheral blood was obtained from 66 daily cannabisusing adults and 55 nonusing adults (Table 1). Users met inclusion criteria of $>5000$ lifetime cannabis use occurrences, as well as daily use in the previous 60 days. Nonusers met the inclusion criteria of having no consecutive 2 days of cannabis use in their lifetime, as well as no cannabis use in the previous 60 days. Urine THC and creatinine metabolites were quantified from urine through gas chromatography/mass spectroscopy in the users. CB1 data were successfully obtained from 105 of these individuals, resulting in a sample of 47 nonusers and 58 users.

\section{Blood draw and lymphocyte isolation}

After informed consent, participants had their blood drawn from antecubital veins according to the standard phlebotomy technique. Approximately $20 \mathrm{~mL}$ of blood was drawn from each participant into two $10 \mathrm{~mL}$ acidcitrate-dextroxse tubes. Lymphocytes were isolated within $24 \mathrm{~h}$ through BD Vacutainer ${ }^{\circledR} \mathrm{CPT}^{\mathrm{TM}}$ Mononuclear Cell Preparation Tubes with sodium heparin (BD Biosciences), which uses an inert gel of a molecular weight less than that of erythrocytes and granulocytes, but greater than that of mononuclear blood cells to separate these layers. After $25 \mathrm{~min}$ of centrifugation at 1.5 relative centrifugal force (RCF), the lymphocyte layer has a distinct cloudy appearance within the mononuclear cell layer and can be siphoned out through transfer pipette. Lymphocytes were then washed with Dulbecco's phosphate-buffered saline (DPBS) and centrifuged again for $25 \mathrm{~min}$ at $1.5 \mathrm{RCF}$, creating a pellet. Thirty-eight of the samples were resuspended in RIPA buffer (Catalog No. R0278-50ML) before a protocol change, in accordance with enzyme-linked immunosorbent assay (ELISA) guidelines. The remaining 42 of the samples were resuspended in $3 \mathrm{~mL}$ DPBS to avoid interactions with sodium dodecyl sulfide, a reagent in RIPA, and horseradish peroxidase used in the ELISA. ${ }^{31}$ All samples were preserved with $30 \mu \mathrm{L}$ Phosphatase Inhibitor Cocktail 3 (Sigma Aldrich Catalog No. P0044), $30 \mu \mathrm{L}$ Phosphatase Inhibitor Cocktail 2 (Sigma Aldrich Catalog No. P5726), and $30 \mu \mathrm{L}$ Protease Inhibitor Cocktail (Sigma Aldrich Catalog No.

Table 1. Demographics of Participants

\begin{tabular}{|c|c|c|c|}
\hline & All $(N=105)$ & Cannabis users $(N=58)$ & Healthy controls $(N=47)$ \\
\hline Males $n(\%)$ & $67(64)$ & $41(71)$ & $26(55)$ \\
\hline Age-mean (SD) & $29.74(8.73)$ & $29.62(7.52)$ & $29.89(10.12)$ \\
\hline Age of onset of regular cannabis use mean (SD) & - & $16.96(11.43)$ & - \\
\hline Education in years mean (SD) & $14.50(2.40)$ & $13.45(2.26)$ & $15.79(1.89)$ \\
\hline \multicolumn{4}{|l|}{ Race } \\
\hline Caucasian & 55 & 33 & 22 \\
\hline African American & 21 & 13 & 8 \\
\hline American Indian/Alaska Native & 3 & 0 & 2 \\
\hline Asian & 10 & 4 & 9 \\
\hline Native Hawaiian or Pacific Islander & 1 & 0 & 1 \\
\hline Multiracial & 10 & 8 & 2 \\
\hline Other & 6 & 3 & 3 \\
\hline Lifetime cannabis problem symptom count $^{\mathrm{b}}$ & - & $1.22(2.32)$ & - \\
\hline Current cannabis problem symptom count ${ }^{\mathrm{b}}$ & - & $1.19(2.32)$ & - \\
\hline \multirow[t]{4}{*}{ Rs2023239 Genotype } & GG: 3 & GG: 3 & GG: 0 \\
\hline & GA: 18 & GA: 14 & GA: 4 \\
\hline & AA: 51 & AA: 27 & AA: 24 \\
\hline & $33 \mathrm{NA}$ & $14 \mathrm{NA}$ & 19 NAs \\
\hline
\end{tabular}

From the Structured Clinical Interview for DSM-IV.

$\mathrm{SD}$, standard deviation. 
P8340). The resulting suspension was then divided into three equal aliquots and frozen at $-80^{\circ} \mathrm{C}$ until $\mathrm{CB} 1$ protein quantification.

\section{Quantification preparation}

Samples were thawed on ice the day of the CB1 and total protein quantification assays. To facilitate sonication, $400 \mu \mathrm{L}$ samples were combined with $100 \mu \mathrm{L}$ sonication buffer (2\% Protease Inhibitor Cocktail, 0.5\% Phosphatase Inhibitor Cocktail 2, 0.5\% Phosphatase Inhibitor Cocktail 3, 10\% glycerol, and $87 \%$ sonication solution), and sonicated in two short bursts. To minimize freeze/thaw cycles and prevent protein shearing, all samples' $\mathrm{CB} 1$ and total protein assays were assayed on the same day.

\section{Protein concentration}

Total protein concentration was quantified through Pierce BCA Protein assay kit (Thermo Fisher Scientific Catalog No. 23225). ${ }^{32}$ Optical density was measured at $562 \mathrm{~nm}$ with a BioTek Absorbance Reader (model ELX800).

CB1 receptors were quantified through the $\mathrm{Hu}$ man CNR1 ELISA Kit (My BioSource Catalog No: MBS2503052), which has demonstrated consistent high antibody specificity for CB1 during tests for protein cross-reactivity, particularly with analogues of $\mathrm{CB} 1$ as reported by the data sheet from MyBioSource found here. ${ }^{31}$ All samples were diluted 1:60 in DPBS, so that the final $\mathrm{CB} 1$ concentration would fall within the detectable range determined by the standard curve. CB1 quantification then occurred according to the kit protocol. Samples were run in duplicate and all reagents were prepared immediately before use. Optical density was determined by absorbance at $450 \mathrm{~nm}$.
Sample concentrations were determined in accordance with each plate's standard curve, and results were calculated according to a four-parameter logistic regression curve. A ratio of $\mathrm{CB} 1$ concentration to total protein concentration was calculated to account for variability between samples that may have been incurred through sample preparation.

\section{Calculation}

Total protein concentration and CB1 concentration were calculated according to each assay's standard curves. These concentrations were then back calculated to determine $\mathrm{CB} 1 /$ total protein ratio in the initial sample concentration, for a normalized CB1 concentration across all subjects.

\section{DNA sample and analysis}

Saliva samples were collected through Oragene Discover kit. ${ }^{33}$ DNA was isolated and CNR1 rs2023239 genotype was determined on a $7900 \mathrm{HT}$ Fast Real-Time PCR System. ${ }^{34}$

\section{Group analyses}

An independent samples $t$-test was run between users and controls to determine any preliminary differences between groups. In users, correlations were performed between normalized CB1 and THC metabolites (Supplementary Fig. S1) in urine, as well as total years of cannabis use (Supplementary Fig. S2). A two-way ANOVA was run between cannabis use status (users vs. nonusing controls) and CNR1 rs2023239 genotype ( $G$ allele carrier vs. noncarriers homozygous for the A allele) to determine the effects of cannabis use and CNR1 genotype on CB1 density (Table 2). Finally, a $t$-test was run to compare $C N R 1$ levels between users

Table 2. Demographics of Participants by Genotype

\begin{tabular}{|c|c|c|c|c|c|c|}
\hline & \multicolumn{2}{|c|}{ All participants } & \multicolumn{2}{|c|}{ Cannabis users } & \multicolumn{2}{|c|}{ Controls } \\
\hline & $\mathrm{AA}(N=51)$ & G carrier $(N=21)$ & $\mathrm{AA}(N=27)$ & G carrier $(N=17)$ & $\mathrm{AA}(N=24)$ & G carrier $(N=4)$ \\
\hline Males, $n(\%)$ & $33(65)$ & $15(71)$ & $20(74)$ & $13(76)$ & $13(54)$ & $2(50)$ \\
\hline Age & $29.67(9.48)$ & $31.10(6.88)$ & $29.41(8.53)$ & $31.24(7.05)$ & $29.96(10.64)$ & $30.5(7.05)$ \\
\hline Age of onset & - & - & $15.69(3.40)$ & $15.30(3.05)$ & - & - \\
\hline Education & $14.14(2.78)$ & $14.61(2.48)$ & $13.33(2.34)$ & $13.53(2.58)$ & $16.04(1.78)$ & $16.75(2.22)$ \\
\hline \multicolumn{7}{|l|}{ Race } \\
\hline Caucasian & 32 & 10 & 17 & 9 & 15 & 1 \\
\hline African American & 4 & 11 & 3 & 8 & 1 & 3 \\
\hline American Indian or Alaska Native & 0 & 0 & 0 & 0 & 0 & 0 \\
\hline Asian & 6 & 0 & 1 & 0 & 5 & 0 \\
\hline Native Hawaiian or Pacific Islander & 0 & 0 & 0 & 0 & 0 & 0 \\
\hline Multiracial & 6 & 0 & 4 & 0 & 2 & 0 \\
\hline Other & 3 & 0 & 2 & 0 & 1 & 0 \\
\hline
\end{tabular}


who have at least one risk $(G)$ allele and users who do not. Because there have been reports of differences between male and female cannabis users, ${ }^{35}$ we performed a post hoc $t$-test to ensure no sex effects were occurring in our sample. Similarly, we performed a post hoc correlation between age and normalized CB1 concentration. ${ }^{14}$

\section{Results}

\section{Main effects}

The protocol resulted in quantification of CB1 protein from human lymphocytes to establish a ratio of CB1 to total protein. Samples were highly concentrated and required dilutions between $40 \times$ and $80 \times$. Cannabis users had an average concentration of $8.10 \mathrm{E}-5$ (standard deviation $[\mathrm{SD}]=4.90 \mathrm{E}-5)$ and nonusing controls had an average concentration of $8.23 \mathrm{E}-5(\mathrm{SD}=4.02 \mathrm{E}-5)$ (Fig. 1). There was no difference in CB1 concentration between cannabis users and nonusing controls, $\mathrm{t}(103)=-0.145$, $p=0.89$ (Fig. 1). In cannabis users, there was no significant correlation between normalized CB1 and THC metabolites, $\mathrm{R}(55)=-0.11, p=0.43$. In addition, there was no correlation between normalized CB1 and years of cannabis use, $\mathrm{R}(55)=0.09, p=0.48$ (Fig. 1). An independent

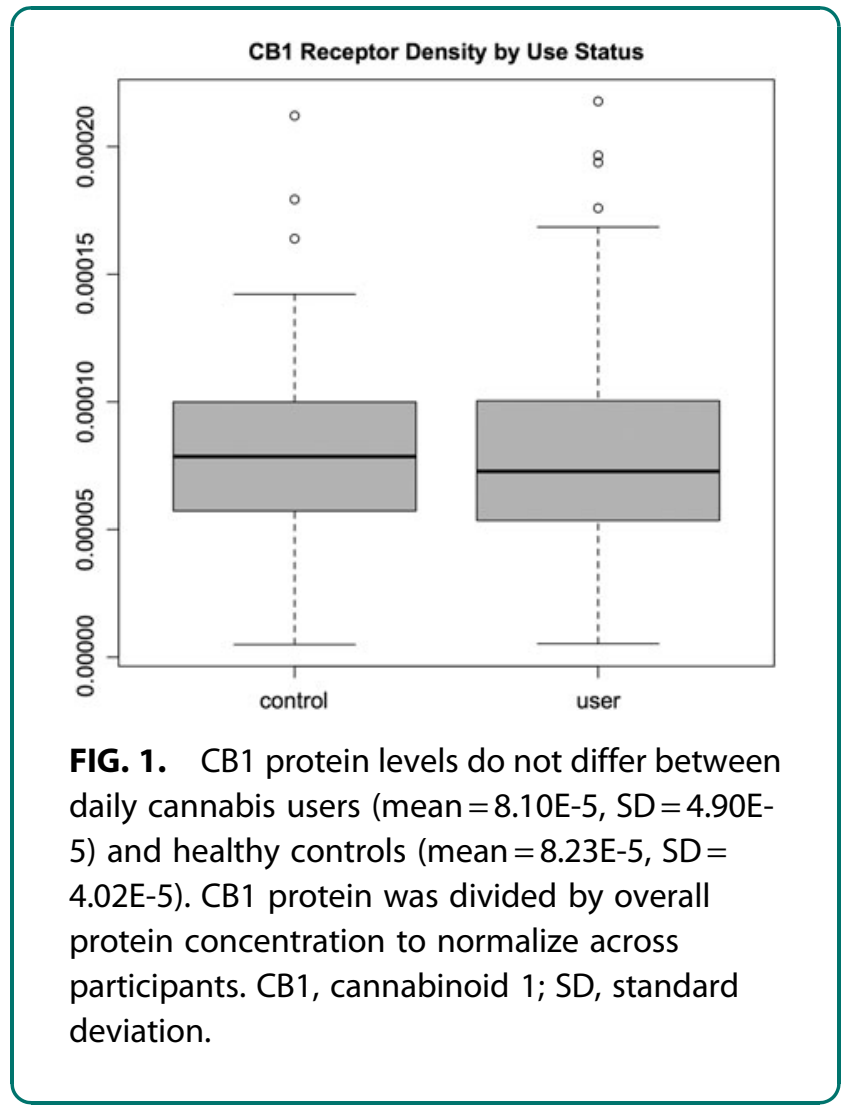

samples $t$-test indicated that there was no difference in CB1 between males and females, $\mathrm{t}(78)=1.81, p=0.07$. There was no relationship between age and CB1, $\mathrm{R}(103)=$ $0.045, p=0.64$.

A two-way ANOVA between users and nonusers carrying the risk allele (GG or GA) indicated a trendlevel interaction between cannabis use status and genotype, such that users who were carriers for the $G$ allele trended toward greater $\mathrm{CB} 1$ protein than both nonusers and users without a $\mathrm{G}$ allele $\mathrm{F}(1,67)=3.56, p=0.06$ (Fig. 2).

A manipulation check using a one-tailed $t$-test was used to examine the differences in individuals with the rs2023239 G allele compared with those without. We calculated a ratio of normalized $\mathrm{CB} 1$ protein in users with the $\mathrm{G}$ allele to the average normalized $\mathrm{CB} 1$ protein in nonusers with the $\mathrm{G}$ allele, and a ratio of $\mathrm{CB} 1$ protein in nonusers with the $G$ allele to the average of normalized $\mathrm{CB} 1$ protein in nonusers without the $\mathrm{G}$ allele. A $t$-test between these two ratios, with a corrected standard error to account for the full sample size including nonusers, indicated that cannabis users with the rs $2023239 \mathrm{G}$ allele had greater $\mathrm{CB} 1$ density than users not carrying the $\mathrm{G}$ allele, $\mathrm{t}(68)=2.1, p=0.038$ (Fig. 3).

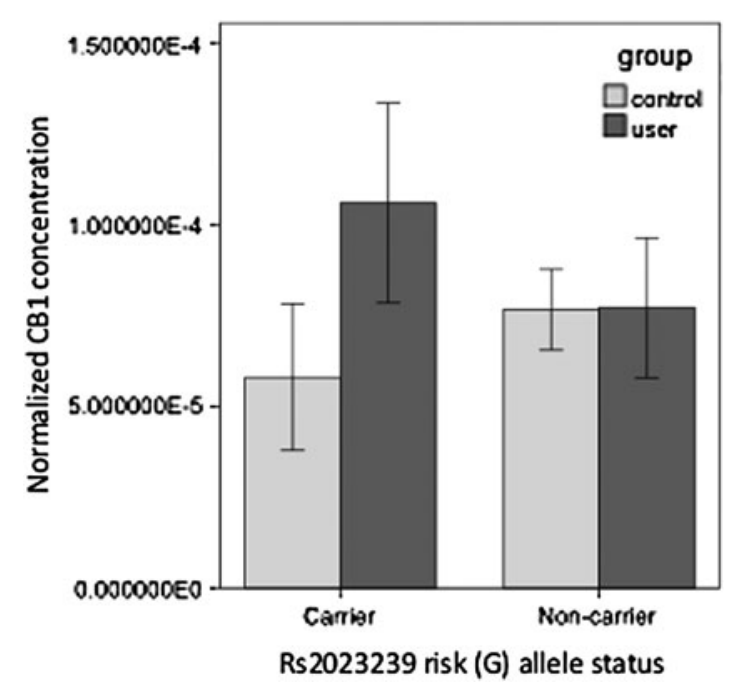

FIG. 2. There is a trend toward a gene by group interaction between cannabis use and rs2023239 risk (G) allele carrier status $F(1,67)=3.56, p=0.06$. Light gray bars indicate control participants; dark gray bars indicate daily cannabis users. Error bars indicate $95 \%$ confidence intervals. 


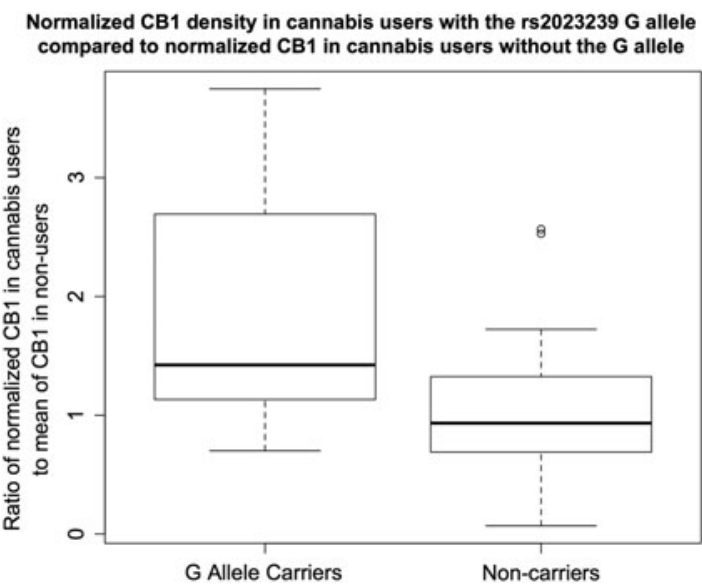

FIG. 3. A t $t$-test between the ratio of protein in cannabis users to the average value in nonusers showed that rs2023239 risk (G) allele carriers had greater normalized CB1 than noncarriers $\mathrm{t}(68)=2.1, p=0.038$.

\section{Post hoc analysis}

To ensure consistent results across the three plates used in this experiment and thereby further control for potential antibody cross-reactivity, ${ }^{36}$ we ran an ANOVA on normalized CB1 concentration across the plates. The results indicated that there was no effect of plate order on protein concentration, $\mathrm{F}(3,59)=1.09, p=0.28$, contributing to our confidence in antibody specificity.

\section{Discussion}

This study demonstrates that peripheral lymphocytes express adequate $\mathrm{CB} 1$ for quantification without need for additional signal amplification and can be normalized into a ratio with total protein concentration for comparisons. These results suggest a gene $\times$ environment effect, such that cannabis users carrying the rs $2023239 \mathrm{G}$ allele had more CB1 than nonusers and non-G allele carriers.

Previous studies have reported brain $\mathrm{CB} 1$ receptor protein downregulation by repeated $\mathrm{CB}$ agonist treatment in the literature, ${ }^{8,12,13,37}$ but findings have not been consistent. ${ }^{38}$ Our findings in lymphocytes demonstrating increased $\mathrm{CB} 1$ density in daily cannabis users are aligned with findings in the brain reporting increased CB1 density postcannabis exposure. ${ }^{10,11}$ However, we acknowledge that lymphocyte $\mathrm{CB} 1$ may be under different post-translational regulatory mechanisms than CB1 in the CNS, such as internalization, degradation, or transport to the membrane.
Other studies have quantified human CB1 density through PET and postmortem methods, but to date, this study is the only documented method for quantifying how $\mathrm{CB} 1$ protein in human peripheral lymphocytes might be affected by rs2023239 genotype and cannabis use. Because measurement of receptor density in the human CNS is difficult, our results expand upon this body of literature by employing a minimally invasive technique to quantify CB1 in humans. Although reports of $\mathrm{CB} 1$ concentrations in the CNS after chronic cannabis exposure are variable, the majority of the literature indicates downregulation of $\mathrm{CB} 1 .^{37}$ Thus, our findings suggest that in participants with the rs2023239 G allele, lymphocyte CB1 may be regulated differently than reports showing $\mathrm{CB} 1$ downregulation in the CNS. This could be because of the differential roles of the ECS in these different tissues, or different post-translational mechanisms, for example, degradation. Furthermore, these results may reflect molecular effects of chronic and substantial THC exposure in peripheral tissue, which if statistically detectable as our results suggest may be informative for the effects of cannabis use overall.

Although data regarding the effects of chronic heavy cannabis use on CB1 density are sparse, they suggest that $\mathrm{CB} 1$ concentration is affected by modulation of downstream signaling as $\mathrm{CB} 1$ modulates GABAergic and glutamatergic signaling pathways. However, to date, it has been unclear how this affects all cannabinoidmediated processes in the long term, and whether there could be a connection between peripheral data and CNS function. ${ }^{39-41}$ This assay provides the first evidence that measurement of peripheral CB1 lymphocytes is a cost-effective, minimally invasive method for measuring susceptibility to cannabis use.

Changes in CB1 as a result of cannabis use are widely reported in the literature. Alternative splicing of CNR1 in those with rs2023239 $\mathrm{G}$ allele is associated with greater binding of CB1 agonists. ${ }^{4,5}$ Thus, the rs $2023239 \mathrm{G}$ allele may indicate greater $\mathrm{CB} 1$ concentrations. $\mathrm{CB} 1$ density is increased postmortem in cannabis users relative to nonusers. ${ }^{38}$ Rs2023239 G allele carriers report greater sensitivity to the rewarding effects of cannabis and exhibit greater withdrawal after abstinence. ${ }^{7}$ Taken together, our finding of a gene by environment interaction, together with the absence of a difference between $\mathrm{CB} 1$ density in cannabis users versus nonusers, suggests the possibility that cannabis use leads to an upregulation of CB1 receptors in those predisposed for greater CB1 binding (i.e., rs2023239 $\mathrm{G}$ allele carriers). In addition, 
these results support previous findings by our group, which identified a cannabis use by rs2023239 genotype interaction on hippocampal volume. ${ }^{42}$ Together, these studies may indicate that the rs2023239 genotype moderates the effects of CB1 agonists, such as cannabis use.

The relationship between expression of $\mathrm{CB} 1$ in the periphery and $\mathrm{CB} 1$ in the CNS has not yet been elucidated, but extant literature supports the importance of genetic variation in neurological functions related to this gene. ${ }^{6}$ Similar work in the fatty acid amide hydrolase gene has shown effects of SNP genotype on peripheral protein density, with associated protein concentrations in the CNS and increased risk for cannabis use disorders. ${ }^{43,44}$ Although the relationship between peripheral and CNS receptor expression is complicated, it is valuable and necessary to characterize, because these proteins are highly regulated by internal and environmental factors. ${ }^{45}$ Thus, CB1 density, in conjunction with the rs2023239 genotype, holds promise for measurement of change in receptor density over time that can be corroborated with CNS CB1. Future work should examine CB1 density in conjunction with other measures of cannabis use, particularly to elucidate the relationship between CB1 expression and behavior. Such a relationship would facilitate the development of the Research Domain Criteria ${ }^{46}$ as well as treatment options for cannabis use disorders.

\section{Limitations}

Lymphocytes are a heterogeneous classification of several cell subtypes and CB1 may be altered in one cell type, but not another. Although this variability may be detectable on an individual basis, it is likely to be averaged out throughout our sample. However, to ensure that lymphocyte heterogeneity is not an issue, Fluorescence Activated Cell Sorting could differentiate subtypes for clear understanding of CB1 in each subtype. This study would benefit from additional specificity controls such as an antigen blockage of the signal or non-CB1R expressing cells and high-CB1R expressing cells, to serve as a negative and positive control, respectively. As our results reached trendlevel significance, this study warrants further examination of these effects in a larger sample size. Finally, future work is necessary to divulge the relationship between CB1 expressed in peripheral lymphocytes and $\mathrm{CB} 1$ expressed in the brain, as well as how these concentrations are affected by daily chronic cannabis use. Importantly, this study serves as the first step toward understanding this relationship.

\section{Conclusions}

In sum, this is the first documented method for quantification of CB1 receptors from peripheral lymphocytes in long-term, daily cannabis users. Using this method, we found a gene by environment interaction indicating CB1 upregulation in cannabis users with the rs2023239 $\mathrm{G}$ allele. This protocol provides a minimally invasive method for examining potential up- or downregulation of a receptor with important psychoactive, immune, and digestive regulatory functions, and holds promise as a potential research and diagnostic tool.

\section{Acknowledgments}

The authors would like to thank the Filbey Lab research assistants for the data collection and processing of samples and Dr. Michael Burton for proofreading the article. This research was funded by NIH R01 1R01DA03034401A1 (Filbey).

\section{Authors Contribution}

F.F. designed the study. A.K. carried out assays, analyses, and wrote the initial draft of the article. L.N. provided technical assistance for the assays and reviewed the article. F.F. and C.M. provided input and helped write the article.

\section{Author Disclosure Statement}

No competing financial interests exist.

\section{References}

1. Elphick MR, Egertová M. The neurobiology and evolution of cannabinoid signalling. Philos Trans R Soc Lond Ser B. 2001;356:381-408.

2. Mackie K. Distribution of cannabinoid receptors in the central and peripheral nervous system. Handb Exp Pharmacol. 2005;168: 299-325.

3. Lupica CR, Riegel AC, Hoffman AF. Marijuana and cannabinoid regulation of brain reward circuits. Br J Pharmacol. 2004;143:227-234.

4. Zhang P-W, et al. Human cannabinoid receptor $1: 5^{\prime}$ exons, candidate regulatory regions, polymorphisms, haplotypes and association with polysubstance abuse. Mol Psychiatry. 2004;9:916-931.

5. Hutchison $\mathrm{KE}$, et al. The incentive salience of alcohol: translating the effects of genetic variant in CNR1. Arch Gen Psychiatry. 2008; 65:841.

6. Filbey FM, Schacht JP, Myers US., et al. Individual and additive effects of the CNR1 and FAAH genes on brain response to marijuana cues. Neuropsychopharmacology. 2010;35:967-975.

7. Haughey HM, Marshall E, Schacht JP, et al. Marijuana withdrawal and craving: influence of the cannabinoid receptor 1 (CNR1) and fatty acid amide hydrolase $(F A A H)$ genes. Addiction. 2008;103:1678-1686.

8. Burston JJ, Wiley JL, Craig AA, et al. Regional enhancement of cannabinoid $C B 1$ receptor desensitization in female adolescent rats following repeated $\Delta$ 9-tetrahydrocannabinol exposure: THC and adolescent CB1 receptor desensitization. Br J Pharmacol. 2010;161:103-112.

9. Zhuang $\mathrm{S}$, et al. Effects of long-term exposure to $\Delta 9$-THC on expression of cannabinoid receptor (CB1) mRNA in different rat brain regions. Mol Brain Res. 1998;62:141-149.

10. Dean B, Bradbury R, Copolov DL. Cannabis-sensitive dopaminergic markers in postmortem central nervous system: changes in schizophrenia. Biol Psychiatry. 2003;53:585-592. 
11. Pagotto U., et al. Normal human pituitary gland and pituitary adenomas express cannabinoid receptor type 1 and synthesize endogenous cannabinoids: first evidence for a direct role of cannabinoids on hormone modulation at the human pituitary level. J Clin Endocrinol Metab. 2001;86:2687-2696.

12. Villares J. Chronic use of marijuana decreases cannabinoid receptor binding and mRNA expression in the human brain. Neuroscience. 2007;145:323-334.

13. Hirvonen J., et al. Reversible and regionally selective downregulation of brain cannabinoid CB1 receptors in chronic daily cannabis smokers. Mol. Psychiatry. 2012;17:642-649.

14. Wong DF, et al. Quantification of cerebral cannabinoid receptors subtype 1 (CB1) in healthy subjects and schizophrenia by the novel PET radioligand [11C]OMAR. Neurolmage. 2010;52:1505-1513.

15. Breivogel CS, Selley DE, Childers SR. Cannabinoid receptor agonist efficacy for stimulating [35S] GTP $\gamma S$ binding to rat cerebellar membranes correlates with agonist-induced decreases in GDP affinity. J Biol Chem. 1998;273:16865-16873.

16. Izzo AA, Sharkey KA. Cannabinoids and the gut: new developments and emerging concepts. Pharmacol Ther. 2010;126:21-38.

17. Löfgren $P$, Sjölin $E$, Wåhlen $K$, et al. Human adipose tissue cannabinoid receptor 1 gene expression is not related to fat cell function or adiponectin level. J Clin Endocrinol Metab. 2007;92:1555-1559.

18. Galiègue S., et al. Expression of central and peripheral cannabinoid receptors in human immune tissues and leukocyte subpopulations. Eur $J$ Biochem FEBS. 1995;232:54-61.

19. Schatz AR, Koh W, Kaminski N. Delta-9-Tetrahydrocanabinol selectively inhibits T-cell dependent humoral immune responses through direct inhibition of accessory T-cell function. Immunopharmacology. 1993;26:129-137.

20. Srivastava MD, Srivastava BIS, Brouhard B. Delta-9-tetrahydrocannabinol and cannabidiol alter cytokine production by human immune cells. Immunopharmacology. 1998;40:179-185.

21. Börner $C$, Bedini $A$, Höllt V, et al. Analysis of promoter regions regulating basal and interleukin-4-inducible expression of the human $C B 1$ receptor gene in T lymphocytes. Mol Pharmacol. 2008;73:1013-1019.

22. Bouaboula M., et al. Cannabinoid-receptor expression in human leukocytes. Eur J Biochem. 1993;214:173-180.

23. Gladkevich A, Kauffman HF, Korf J. Lymphocytes as a neural probe: potential for studying psychiatric disorders. Prog Neuropsychopharmacol Biol Psychiatry. 2004;28:559-576.

24. Grimsey NL, Goodfellow CE, Scotter EL, et al. Specific detection of CB1 receptors; cannabinoid $\mathrm{CB} 1$ receptor antibodies are not all created equal! J Neurosci Methods. 2008;171:78-86.

25. Maccarrone $M$, Valensise $H$, Bari $M$, et al. Progesterone up-regulates anandamide hydrolase in human lymphocytes: role of cytokines and implications for fertility. J Immunol. 2001;166:7183-7189.

26. Onaivi ES, et al. Expression of cannabinoid receptors and their gene transcripts in human blood cells. Prog Neuropsychopharmacol Biol Psychiatry. 1999;23:1063-1077.

27. Piszcz JA, Lemancewicz D, Kloczko J, et al. Cannabinoid receptors expression in bone marrow trephine biopsy of chronic lymphocytic leukaemia patients treated with purine analogues. Exp Oncol. 2007;29:221-225.

28. Rotter A, Bayerlein K, Hansbauer M, Weiland J, Sperling W, Kornhuber J, Biermann T. CB1 and CB2 receptor expression and promoter methylation in patients with cannabis dependence. Eur Addiction Res. 2013;19:13-20.

29. Hirvonen J., et al. Reduced cannabinoid CB1 receptor binding in alcohol dependence measured with positron emission tomography. Mol Psychiatry. 2013;18:916-921.

30. Filbey FM, et al. fMRI study of neural sensitization to hedonic stimuli in long-term, daily cannabis users. Hum Brain Mapp. 2016;37: 3431-3443.

31. MyBiosource, Human CNR1 (Cannabinoid Receptor 1, Brain) ELISA Kit.pdf. Available at: https://www.mybiosource.com/images/tds/ protocol_manuals/800000-9999999/MBS2503052.pdf

32. Bradford MM. A rapid and sensitive method for the quantitation of microgram quantities of protein utilizing the principle of protein-dye binding. Anal Biochem. 1976;72:248-254

33. Birnboim HC. DNA yield with an Oragene ${ }^{\circledR}$ self-collection kit. DNA Genotek: Ottawa, Canada, 2011.

34. Rogers NL, Cole SA, Lan $\mathrm{H}-\mathrm{C}$, et al. New saliva DNA collection method compared to buccal cell collection techniques for epidemiological studies. Am J Hum Biol Off J Hum Biol Counc. 2007;19:319-326.

35. Ketcherside A, Baine J, Filbey F. Sex effects of marijuana on brain structure and function. Curr Addict Rep. 2016;3:323-331.

36. Cécyre B, Thomas S, Ptito $M$, et al. Evaluation of the specificity of antibodies raised against cannabinoid receptor type 2 in the mouse retina. Naunyn Schmiedebergs Arch Pharmacol. 2014;387:175-184.

37. Sim-Selley LJ. Regulation of cannabinoid CB1 receptors in the central nervous system by chronic cannabinoids. Crit Rev Neurobiol. 2003;15:91-119.

38. Dean B, Sundram S, Bradbury R, et al. Studies on [3H]CP-55940 binding in the human central nervous system: regional specific changes in density of cannabinoid-1 receptors associated with schizophrenia and cannabis use. Neuroscience. 2001:103:9-15.

39. Bass CE, Welch SP, Martin BR. Reversal of $\Delta 9$-tetrahydrocannabinol-induced tolerance by specific kinase inhibitors. Eur J Pharmacol. 2004:496:99-108.

40. Martin BR. Role of lipids and lipid signaling in the development of cannabinoid tolerance. Life Sci. 2005;77:1543-1558.

41. Whitlow CT, Freedland CS, Porrino LJ. Functional consequences of the repeated administration of $\Delta 9$-tetrahydrocannabinol in the rat. Drug Alcohol Depend. 2003;71:169-177.

42. Schacht JP, Hutchison KE, Filbey FM. Associations between cannabinoid receptor-1 (CNR1) variation and hippocampus and amygdala volumes in heavy cannabis users. Neuropsychopharmacology. 2012;37:2368-2376.

43. Boileau I, et al. The fatty acid amide hydrolase $\mathrm{C} 385 \mathrm{~A}$ variant affects brain binding of the positron emission tomography tracer [11C]CURB. J Cereb Blood Flow Metab. 2015;35:1237-1240.

44. Boileau I, et al. Fatty acid amide hydrolase binding in brain of cannabis users: imaging with the novel radiotracer [(11)C]CURB. Biol Psychiatry. 2016;80:691-701.

45. Matias I, Bisogno T, Di Marzo V. Endogenous cannabinoids in the brain and peripheral tissues: regulation of their levels and control of food intake. Int J Obes. 2006;30S1:S7-S12.

46. Sanislow CA, Quinn KJ, Sypher I. NIMH Research Domain Criteria (RDoC) In The encyclopedia of clinical psychology. Cautin RL, Lilienfeld SO, (Eds.) John Wiley \& Sons, Inc.: Hoboken, NJ, 2015, pp. 1-6.

Cite this article as: Ketcherside A, Noble $\sqcup$, Mclntyre CK, Filbey FM (2017) Cannabinoid receptor 1 gene by cannabis use interaction on CB1 receptor density, Cannabis and Cannabinoid Research 2:1, 202-209, DOI: 10.1089/can.2017.0007.

Abbreviations Used
$\mathrm{CB} 1=$ cannabinoid 1
$\mathrm{DPBS}=$ Dulbecco's phosphate-buffered saline
$\mathrm{ECS}=$ endocannabinoid system
$\mathrm{ELISA}=$ enzyme-linked immunosorbent assay
$\mathrm{PCR}=$ polymerase chain reaction
$\mathrm{PET}=$ positron emission tomography
$\mathrm{SD}=$ standard deviation
$\mathrm{SNP}=$ single nucleotide polymorphism
$\mathrm{THC}=$ delta-9-tetrahydrocannabinol

\section{Publish in Cannabis and Cannabinoid Research}

Cannabis and

Cannabinoid

Research

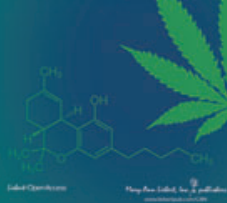

- Immediate, unrestricted online access

- Rigorous peer review

- Compliance with open access mandates

- Authors retain copyright

- Highly indexed

- Targeted email marketing 